\title{
Influencers in the Political Conversation on Twitter: Identifying Digital Authority with Big Data
}

\author{
Andreu Casero-Ripollés
}

Citation: Casero-Ripollés, A.

Influencers in the Political

Conversation on Twitter: Identifying

Digital Authority with Big Data.

Sustainability 2021, 13, 2851. https://

doi.org/10.3390/su13052851

Academic Editor: Ignacio Aguaded

Received: 15 February 2021

Accepted: 3 March 2021

Published: 6 March 2021

Publisher's Note: MDPI stays neutral with regard to jurisdictional claims in published maps and institutional affiliations.

Copyright: (C) 2021 by the author. Licensee MDPI, Basel, Switzerland. This article is an open access article distributed under the terms and conditions of the Creative Commons Attribution (CC BY) license (https:/ / creativecommons.org/licenses/by/ $4.0 /)$.
Department of Communication Sciences, School of Humanities and Social Sciences, Universitat Jaume I de Castelló, 12071 Castelló de la Plana, Spain; casero@uji.es; Tel.: +34-964729911

\begin{abstract}
Interactivity is a defining characteristic of social media. Connections among users shape the network and have a direct impact on the political conversations that take place on digital platforms. In the hybrid media system, digital discussions can have an impact on both the agenda of mainstream media and the offline political life. In this context, determining who and how social influence is exercised is crucial. My objective is to identify the influencers with the greatest digital authority to guide and determine the political conversation on Twitter. For this, I have studied the process to form a Government in Spain. Machine learning techniques are used on a big data sample of 127.3 million tweets. The analysis is based on social network analysis and uses eigencentrality, a measure that determines the digital authority of users. This study focuses on the 250 accounts of the most prominent influencers. The results show that the political and media elites extend their leading roles as influencers in the digital environment. However, there is also evidence of the beginning of the breakdown of its monopoly on digital public debate and its opening to new social actors. Additionally, the data demonstrate the importance of the external socio-political context as a determining element of the exercise of social influence in the political conversation on Twitter.
\end{abstract}

Keywords: Twitter; social influence; digital authority; social media; political communication; political conversation; influencers

\section{Introduction}

Interactivity is one of the main characteristics that define social media. These digital platforms have managed to transfer social connections and relationships to the online environment while transforming them into technological connectivity. In this way, users build potentially broad communities by connecting with each other [1]. These interactions shape the network and have a direct impact on the political conversation that unfolds in digital media. In a context marked by a hybrid media system [2], these digital discussions have an increasing incidence in conventional media, being able to shape their content [3], and in public debate outside the Internet. This offers opportunities to establish the public agenda and influence the framing and construction processes of shared meanings socially linked to political events $[4,5]$. For this reason, it is essential to analyze how the interactions in social media related to the political sphere are articulated and, particularly, which actors enjoy the greatest influence to have an effect in the digital political conversation. In this context, determining who and how social influence is exercised is crucial.

Social influence is configured as an essential property to influence the dynamics of political communication. It can be defined as intentional or unintentional communication that produces changes in the attitudes, beliefs, intentions, motivations, or behaviors of another person [6]. It activates interpersonal processes that are non-coercive and highly dynamic [7]. Social influence is multifactorial since one could be influenced by someone else based on the authority and social status, reciprocity, commitment and coherence, sympathy, scarcity, or social sanction [8].

Research on social influence has devoted special attention to identifying and characterizing people with the greatest capacity to persuade others. These are known as influencers, 
who are also users operating in the digital environment and are characterized by being well informed, respected, having authority within a community, and being strategically well related within their network of contacts [9]. This concept derives from the idea of opinion leader, central to communication research in the mid-20th century [10]. Social media placed influencers in the center due to their ability to gain prominence in the digital conversation on the network and to influence other people [11]. Due to the communicative characteristics of digital platforms, even normal citizens can be configured as influencers. The extent of action of these users can encompass various areas such as education [12] or journalism $[13,14]$, and various digital platforms such as Twitter, YouTube, or Instagram among others $[15,16]$. The digital environment can empower people with limited influence in the offline world [17]. However, it can also help to strengthen the position of those actors who have a high capital of social influence outside the Internet.

My objective is to identify the main influencers on Twitter in a highly relevant political process: the negotiation process to form a Government in Spain. To do this, machine learning techniques are used on a big data sample made up of 127.3 million tweets. Specifically, I use a specific measure of centrality from social network analysis: eigencentrality. This indicator is associated with the digital authority that each user accumulates in their interactions on Twitter. Taking this measure, the 250 accounts of the most prominent influencers are identified and analyzed. The detection of these influential actors is crucial to know who may have a greater capacity to guide and determine the political conversation on Twitter.

\section{Literature Review}

\subsection{Changes in the Way of Influencing Social Media}

Social media are reconfiguring the ways and dynamics of exercising social influence. These digital platforms affect the relationships between political actors, the media, and citizens. However, it is open to determine if they promote a breakdown of the hierarchies of control and power of the information flows, democratizing the field of political communication, or, on the contrary, if they strengthen the dominant structures and the protagonism of the traditional elites, perpetuating inequalities [18]. Some research shows that social media have allowed new social actors, generally located on the margins such as citizens, to exert social influence in the digital environment [19]. These digital platforms impose low barriers enabling any user to target potentially wide audiences. Various studies have shown that emerging political actors or outsiders, such as Podemos [3] or the $15 \mathrm{M}$ movement in Spain [20], have effectively used social media to influence the agenda public, capture the attention of the mainstream media and manage to place their issues and frames at the center of public debate. Similarly, in the case of the Occupy Wall Street protests, public figures and alternative media organizations focused public attention on economic inequality through digital platforms, generating a dynamic of social influence from the margins capable of affecting public debate [21].

The increase in facilities to access digital media for the creation and dissemination of communicative content has led to the multiplication of political and social actors, who compete to try to shape the agenda and public debate [2]. The horizontal nature of social media has opened processes of democratization of information [22] and redistribution of power that can alter established scenarios, coming from the era of mass communication. In this historical period, politicians and journalists were the central actors in determining the themes, contents, and limits of public debate [23]. That made them great influencers on the mainstream communication scene.

However, some research suggests that journalists and politicians have witnessed how their capacity for social influence has weakened in the digital environment. Social media have opened the public discussion to new actors, increasing competition when it comes to articulating, and affecting, the political debate $[24,25]$. This phenomenon is causing a break in the monopoly of the media and political elites on political conversation and public opinion [2,14]. As a consequence, the authority and social influence of these traditional actors may be reduced when persuading and convincing citizens online. 
At the same time, other research suggests that social media is helping to reinforce the power and positions of those actors who were already influential outside the digital environment, especially traditional political actors, journalists, and the mainstream media [26,27]. This is because digital platforms impose the rules of the attention economy. These establish asymmetries in terms of attention between social actors based on their power and previous position outside the Net [28]. These inequalities mean that not all users have the same possibilities and opportunities to generate social influence on the online scene $[29,30]$. The political and media elites thus impose their dominance again, now in the digital environment [31-33]. Along these lines, some authors suggest that social media favors decentralization and citizen adherence more than openness and deliberation [34]. This leads to the predominance of a small minority. Less than $2 \%$ of Twitter users create $50 \%$ of the content in circulation, generating biases in terms of the ability to lead the digital political conversation [35]. Something similar happens in interactions in networks since a few nodes monopolize a large part of the links and are in charge of sustaining the digital structure, while the rest play a secondary role and are even dispensable [36].

\subsection{Influence and Digital Authority}

The identification of social influence in digital media does not respond to a single variable because it is a multidimensional phenomenon endowed with various components. When determining digital social influence, three indicators can be distinguished: popularity, activity, and authority [37]. The first is the notoriety of the user or how he is known. A user is popular when he is recognized by many other users on the network. Although the simplest evidence of popularity is the number of followers, there are others such as the ratio between followers and followed (followers to followee ratio). This category associates social influence with a potentially large audience of followers on which it is feasible to impact. However, greater popularity does not necessarily lead to a greater capacity to gain prominence in the political conversation on Twitter [9].

The activity is related to the frequency, consistency, and amount of content created on social media by a user. Therefore, the most active users can produce a high volume of information and can disseminate it through their network of contacts. In this sense, measures such as the number of tweets published and the number of retweets generated are used. Social influence is linked here with the ability to create messages and content that can potentially influence the public agenda and the framing processes of political events. However, user's productivity is not always associated with the capacity to determine the digital political conversation [37].

Finally, the third is the digital authority of a user. It is a measure of the social influence of a node in a network. It is measured from the eigenvector centrality, also called eigencentrality. This item assigns relative scores to all nodes in a network, that is, to all its users, considering that the connections to high-scoring nodes contribute more to the node's equal score than connections to a network with low scores [38]. A high eigencentrality means that a node is connected to users who are highly connected [39]. In other words, users with high values have an internal authority within a network due to the mentions received in the conversation and by who mentions them [32]. That is, they receive the highest level of support from the members of a network, generating the highest level of interaction. Therefore, the position of users in the general structure of a network, in terms of centrality, and the relationships between them can be studied, and their ability to influence interactions in that network can be assumed [40]. Obtaining a high value in this indicator presupposes that the user can affect the political conversation in a network and become an influencer [41].

\section{Methodology}

\subsection{Research Gaps and Objectives}

Discovering who controls the the flow of political information in digital media has been a preferred goal of the research on digital political communication. The social actors 
who do this successfully dominate the online public debate and exert their social influence by shaping the public agenda. This gives them high visibility and therefore can have a great effect in persuading other people. Previous research has adopted two main positions regarding this topic. On the one hand, those who defend the extension of the dominance of political and media elites now in the digital environment. On the other hand, those who claim that new actors, as citizens or social movements, gain prominence in social media, breaking the monopoly of the journalists and politicians. However, more research is still needed to answer this complex question.

It has not yet been possible to establish which are the actors that shape the political conversation on Twitter. Previous analyses have focused on the strategies and activities of these actors on this platform, but have not paid enough attention to their incidence and effectiveness to shape the digital debate. This is a research gap that this article aims to solve by offering data on the degree of digital authority of the different types of social actors that participate in the digital discussion. This will provide evidence of who controls and dominates the flow of information during online political conversation, exerting social influence. Considering this, the objectives of this research are:

O1. Identify those users who achieve a greater capacity for social influence on Twitter during the political conversation related to a relevant event.

O2. Determine which types of actors have the greatest numerical presence within the influencers in the political discussion on Twitter.

O3. Discover which groups of actors within the influencers obtain the greatest digital authority to have an effect and gain prominence in the public debate on Twitter.

I hope to obtain findings that overcome the gaps in the previous literature that have focused on specific cases, such as single emerging political parties or unique social movements, and have generally used samples with a reduced volume of data. My study goes beyond these limitations by analyzing a case that is central to political life and that has a broad temporal extension ( 6 months). In addition, a big data sample based on 127.3 million tweets is used. This offers a high level of representativeness and soundness to the findings.

\subsection{Data Collection and Processing}

This research is focused on Twitter because it is the social media most used by politicians and journalists. The presence of these two types of actors is very high in this digital medium compared to others [42,43]. Moreover, this platform is the prominent stage where communication, conversation and digital discussion associated with political communication takes place.

The data has been collected by taking as a case study the negotiation process for the formation of a Government in Spain that took place between the elections of 2015 and 2016. The period analyzed is, from the day after the general election of 20 December 2015, to the dissolution of the Parliament and the calling of new elections, on 2 May 2016, due to the impossibility of forming a Government. This is a total of 133 days. Therefore, the sample compiles the political conversation on Twitter about a highly relevant political process for political dynamics. This is due to the fact that formation of the Government is crucial for the citizens because it can directly affect their daily life. The political centrality of this process favors the emergence of public debate and the possibility of locating the most influential users on Twitter. Spain is a multi-party parliamentary system integrated in the European Union. This case study allows obtaining data and observations that can be extended to other countries with a similar political system and to other countries in the European area.

To obtain the data, accounts of Twitter users linked to three networks were selected, represented by three Spanish cities: Madrid, Barcelona, and Valencia. The choice of these cities is justified by the number of inhabitants and by their relevance and prominence in the political life of the country. Madrid is the center of the political institutions of the State (Parliament and Government), Barcelona is immersed in the independence process that aspires to create a sovereign State, separating from Spain, and Valencia occupies a secondary 
position concerning the political and economic centers of power and media. In order words, it has a lower hierarchy, or a lower rank, in the Spanish political system to determine the agenda and public debate. Users were selected because they were representative accounts on Twitter of actors from the political sphere (leaders and parties) and the media (journalists and opinion-makers). Applying the criteria of a strategic sample [44], the selection was made considering the number of followers of each account and their ability to create opinion in the political arena; 145 Twitter accounts were selected and analyzed. Subsequently, their followers have been incorporated into the analysis in an automated way. A total of 24 million accounts have been obtained.

Due to the large size of the data collected, it was necessary to limit the analysis to 10,000 Twitter accounts for each of the three networks studied. For this, it was determined which accounts were more influential, according to a PageRank calculation. This indicator establishes the quality and incidence of a node, or account, in a network based on the number and relevance within that network of its followers [45]. After eliminating the duplications, the total number of analyzed users was 24,389 Twitter accounts. Despite starting from three different networks, it was detected that these political communities were not watertight compartments since there were users that operate in more than one network at the same time. Disaggregating the data, it can be specified that 19,672 accounts had a presence in a single network. A total of 3823 accounts operated in two networks. Finally, 894 accounts, equivalent to $3.66 \%$ of the total, had access to the political conversation in the three networks simultaneously.

\subsection{Network Analysis Procedures}

Networks are structures made up of nodes (users or accounts within the network) and the ties or links (relationships or interactions) that connect them. In this research, the networks are represented by the online political community generated on Twitter around each of the three cities studied. The analysis of the centrality of the users, or accounts, in a network constitutes a basic element to explore the interactions that take place between actors and to identify the most influential ones. One of the basic functions of social network analysis (SNA) is the distinction between central and peripheral users to determine their level of importance and their social influence. Users endowed with greater centrality have a greater capacity to lead interactions on the network and the digital political conversation. The most appropriate measure of centrality to determine the level of social influence and digital authority of a user is the eigenvector centrality or eigencentrality (EC) [37,38]. This indicator ranges from 0 to 1 , the latter being the highest degree of digital authority of a user on a network.

In the application of the SNA, machine learning techniques have been used. First, the tweets related to the negotiations for the formation of the Government published by the 24,389 accounts analyzed were obtained automatically. Likewise, as a control mechanism, the news generated by the formation of the Government have been manually coded each day. These have been incorporated into machine learning analysis to automatically associate the tweets related to each informative item. Eventually, the tweets whose relationship with the news about the formation of Government were potentially doubtful have been manually removed. The final sample responds to the big data parameters since it is made up of 127.3 million tweets.

For the study of digital authority, the eigencentrality of each user in each of the three networks analyzed has been calculated. Subsequently, for this analysis, the 250 users, or accounts, with the highest eigencentrality were selected. To locate these actors, I used the average of the EC registered in the three networks analyzed simultaneously. The data is presented individually and also by typology. A distinction has been made between seven groups: (a) candidates (political leaders running for the presidency), (b) other politicians, (c) political parties, (d) journalists, (e) media, (f) opinion-makers, (actors who operate in the field of opinion and political analysis and not in the information domain), and (g) citizens. 


\section{Results: Identification of the Main Influencers in the Political Conversation on Twitter Based on Their Digital Authority}

\subsection{Numerical Presence of Influencers in the Political Conversation on Twitter}

First, I analyzed the numerical presence of influencers in quantitative terms in the political conversation on Twitter about the negotiation process for the formation of a Government in Spain. The largest group within the 250 most influential users are political actors. This is due, in the first place, to the importance assumed by other politicians (Figure 1). These actors account for $42.11 \%$ of the total. The candidates and parties could also be added. Political leaders represented $1.62 \%$ of all actors. However, it is important to note that all the members of this group (four in total) are among the 250 most influential users. For their part, political parties account for $2.43 \%$ of the total. The high presence of subjects from politics can be explained by the political nature of the event analyzed. The negotiations for the formation of a Government are configured as a key moment for political actors. This leads them to develop the maximum communication effort and to try to obtain the maximum degree of social influence in the public debate on Twitter. This results in an increase in their access within the group of influencers according to the results obtained.

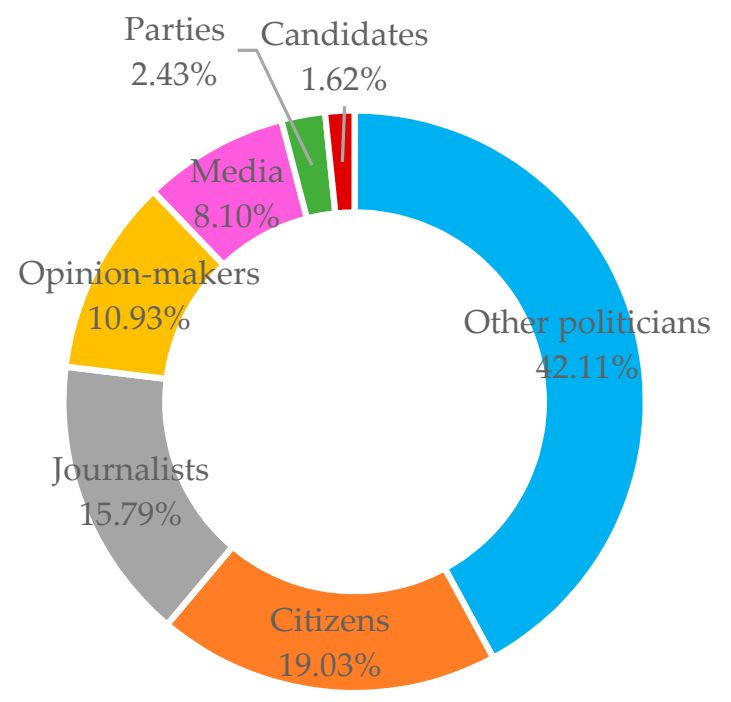

Figure 1. Number of influencers per type ( $n=250$ Twitter users). Source: Own elaboration.

The second largest group corresponded to citizens where $19.03 \%$ of the 250 users with the greatest digital authority in the political conversation on Twitter about the case analyzed are citizens (Figure 1). This data shows the high interest of citizens in the digital debate on the formation of a Government and their willingness to try to shape it. Third, journalists appeared; $15.97 \%$ of the 250 actors with the highest eigencentrality are news workers. The social and political relevance of the event studied, on the one hand, and its ability to overcome informational selection and become news, on the other, caused a significant presence of journalists. Participating in the political conversation on Twitter not only helps to put information in circulation but also tries to influence the digital discussion.

The fourth group according to their quantitative presence is opinion-makers. These actors represent $10.93 \%$ of the 250 most influential users (Figure 1). These individuals focus on political analysis and the dissemination of opinions. This implies a strong orientation towards the exercise of social influence, since obtaining sufficient digital authority is key for them. Despite this, their degree of presence is lower than that of journalists who operate in the field of news, where subjectivity and opinion are restricted. The fifth group in numerical terms corresponds to the media; $8.1 \%$ of the 250 most relevant influencers correspond to this type of actor. Finally, the last positions are held by political parties $(2.43 \%)$ and candidates $(1.62 \%)$ respectively. 
These data offer a general overview of the interactions and dynamics of influence that occur within political conversations on Twitter. In addition, the analysis offers information on the type of influencers who participate in it. However, not all the 250 users analyzed have the same level of digital authority and, therefore, of social influence. On the contrary, there are significant differences between them. To analyze this, it is necessary to focus on the highest positions in the ranking of the digital authority. To do this, I selected the users who exceeded a 0.5 eigencentrality $(\mathrm{EC}>0.50)$. The selection of this cut-off value is motivated by being above $50 \%$ of the maximum value that this indicator can assume. Only 26 exceeded that figure (Table 1). In other words, the highest levels of digital authority are concentrated in only $10.4 \%$ of the total of the 250 most influential actors. Considering the entire sample of actors analyzed (24,389 accounts), only $0.10 \%$ of users have the highest degree of social influence to lead political conversation on Twitter.

Table 1. Influencers with the highest digital authority $(\mathrm{EC}>0.50)$ in the political conversation on Twitter about the negotiation process for the formation of a Government in Spain. Source: Own elaboration.

\begin{tabular}{cccc}
\hline Rank & Actor & Typology & Eigencentrality \\
\hline 1 & Ignacio Escolar & Journalist & 0.786997083 \\
2 & PSOE & Political party & 0.706532164 \\
3 & Europa Press & Media & 0.651858492 \\
4 & Jordi Evole & Journalist & 0.644632466 \\
5 & Ana Pastor & Journalist & 0.628756421 \\
6 & Público & Media & 0.622736169 \\
7 & El País & Media & 0.621643508 \\
8 & Alfredo Pérez Rubalcaba & Other politicians (PSOE) & 0.60958261 \\
9 & eldiario.es & Media & 0.601095483 \\
10 & Julia Otero & Journalist & 0.600774466 \\
11 & Cadena SER & Media & 0.592934826 \\
12 & Pedro Sánchez & Candidate (PSOE) & 0.592028256 \\
13 & Àngels Barceló & Journalist & 0.556088755 \\
14 & Huff Post & Media & 0.552359586 \\
15 & Pablo Iglesias & Candidate (Podemos) & 0.552238101 \\
16 & Jesús Maraña & Journalist & 0.546624497 \\
17 & Carme Chacón & Other politicians (PSOE) & 0.543506924 \\
18 & Miquel Iceta & Other politicians (PSOE) & 0.536300656 \\
19 & Vilaweb & Media & 0.53239295 \\
20 & Fernando Garea & Journalist & 0.530605927 \\
21 & Antoni Gutiérrez Rubi & Opinion-maker & 0.529979083 \\
22 & Agencia EFE & Media & 0.527059663 \\
23 & Gaspar Llamazares & Other politicians (IU) & 0.527027224 \\
24 & Ada Colau & Other politicians (Podemos) & 0.50394449 \\
25 & 20M & Media & 0.502605298 \\
26 & Sonia Sánchez & Opinion-maker & 0.500221398 \\
\hline & & &
\end{tabular}

Table 1 presents the ranking of the most relevant influencers of the case studied. The user with the greatest digital authority is a journalist (Ignacio Escolar, EC: 0.786997983). The presence of two other journalists in the top five (Jordi Évole and Ana Pastor) is also important. In total, $26.92 \%$ of the 26 most influential users are journalists (Figure 2). This confirms the high capacity of these types of actors to access the digital political conversation and influence it. 


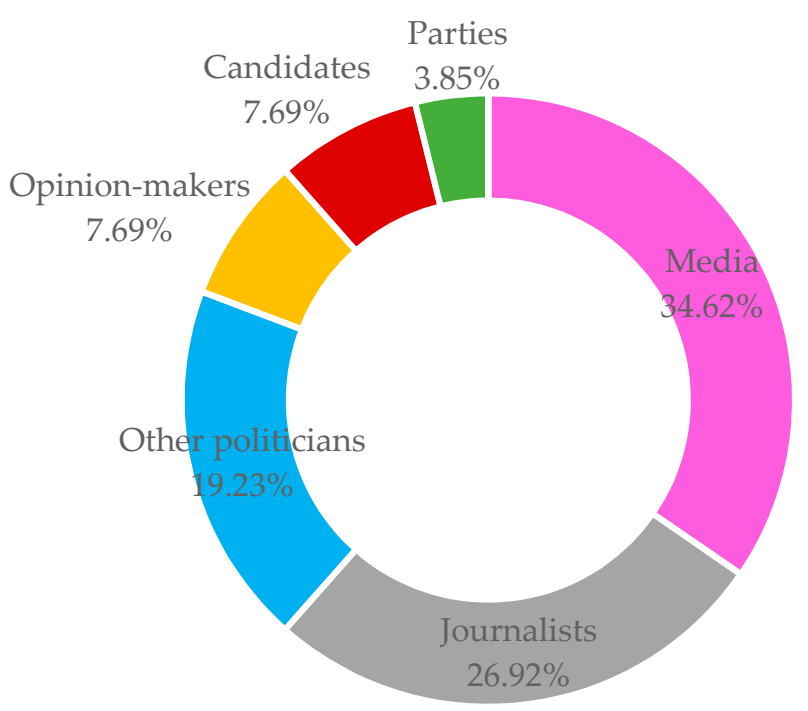

Figure 2. Number of influencers with the highest level of digital authority per typology $(\mathrm{n}=26$ Twitter users with EC > 0.50). Source: Own elaboration.

Among the first positions, several media also appear (Table 1). Some are traditional actors of the Spanish media system (Europa Press, El País, Cadena SER, Agencia EFE, and $20 \mathrm{M}$ ). However, others are recent digital news media with an online version only (Público, eldiario.es, Huff Post, and Vilaweb). This demonstrates the hybridization between old media, coming from outside the Internet, and new media, born and developed in the digital environment. Together, the media have a prominent presence at the highest levels of digital authority; $34.62 \%$ of the most influential users are of this type (Figure 2). Adding this percentage to that corresponding to journalists, $61.54 \%$ of the actors with the highest level of digital authority belong to the media system. This shows their great role as influencers to determine the political conversation on Twitter.

Another group that has a notable presence among the most relevant influencers in the digital public debate are politicians. This is foreseeable given its active role in the process of government formation. Despite this, they are outperformed by media actors. The total number of actors from the political system represented $30.77 \%$ of the total compared to $61.54 \%$ of the sum of media and journalists. Specifically, of the 26 users with the highest digital authority, $19.23 \%$ are other politicians, $7.69 \%$ are candidates, and $3.85 \%$ are political parties (Figure 2). Only half of the candidates accessed the most prominent group of influencers. They are Pedro Sánchez (EC: 0.592028256), who starred in the negotiations to form a Government in the case studied, and Pablo Iglesias (EC: 0.552238101), leader of Podemos, a left-wing populist party (Table 1).

Finally, opinion-makers represented $7.69 \%$ of the 26 actors with the greatest digital authority in the political conversation on Twitter (Figure 2). In consequence, only two users of this type can access this group, where the highest levels of digital influence are concentrated. These two opinion-makers occupied low positions within this ranking (Table 1). It is important to note that there are no citizens among the most influential actors (Figure 2). Despite being, quantitatively, one of the most numerous groups within the 250 most influential users since they represent $19.03 \%$ of the total (Figure 1), they do not place any actor within the group of the 26 users with the greatest digital authority (Figure 2). The highest digital authority of an actor in this group is reached by @sandradespacho (Sandra Pérez García), who ranked in the 52nd position with an EC: 0.425299235 . This suggests the limitations of citizens to obtain high values of eigencentrality and also shows their restricted ability to shape the public debate on Twitter. 


\subsection{Level of the Digital Authority of Influencers in the Political Conversation on Twitter per Type and Network}

Second, I proceeded to identify the influencers' level of digital authority. To do this, I studied the different types of actors in each of the three networks analyzed. This enabled me to observe the groups that predominate in the exercise of social influence in the political conversation on Twitter. This way, I complemented the analysis of the numerical presence of influencers with the study of their digital authority to determine the discussion and interaction on this digital platform.

The analysis of the three networks shows the existence of significant differences between the multiple digital political communities in which the political conversation takes place (Figure 3). In Madrid, the digital authority is concentrated on the candidates, on the one hand, and the media and journalists, on the other (Table 2). The centrality of Madrid for the Spanish political life causes political leaders, who were the protagonists of the negotiations to form a Government, to accumulate a high social influence in the digital public debate. Furthermore, the interaction between these and the media actors acquires a great prominence on Twitter in this political community. In this particular context, these individuals have a significant capacity to shape the definition of the political reality, the issues and frames in circulation, and the formation of opinion in the digital environment. The rest of the groups (parties, other politicians, and opinion-makers) achieve a low level of digital authority since their eigencentrality ranges between 0.26 and 0.37 (Table 2). This reveals the difficulties of these types of actors to have an effect in the political conversation on Twitter in Madrid. Citizens register a very low digital authority (EC: 0.06096887). This shows its minimal relevance to influence the themes and frames of the digital public debate on this network.

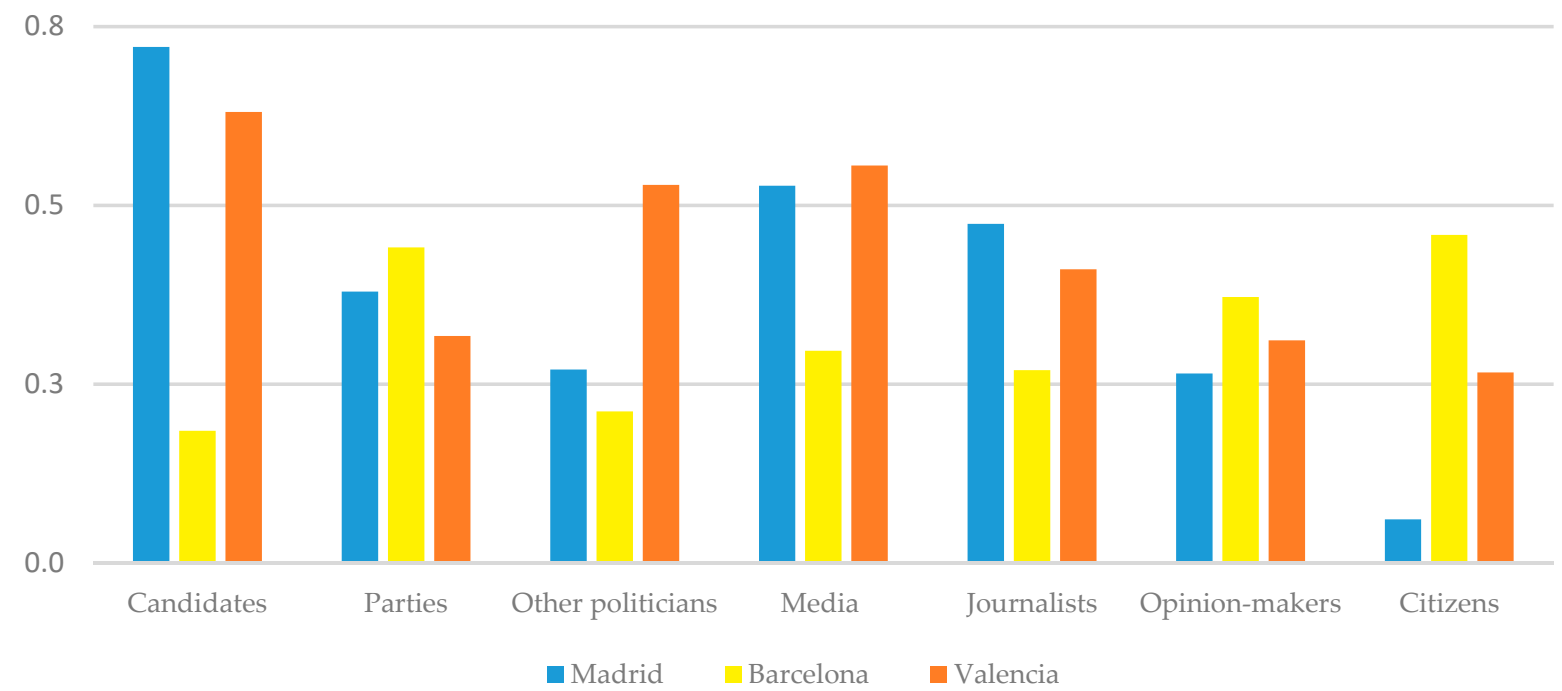

Figure 3. Eigencentrality of the types of influencers per network. Source: Own elaboration.

Madrid is configured as a highly competitive network. This is because the eigencentrality levels of individual users are lower compared to those recorded in the other two networks (Figure 3). This makes it more difficult for social actors to be influential in the digital political conversation here. Access to a position of digital authority is limited to a small number of actors, including candidates, the media, and journalists. 
Table 2. Eigencentrality of the types of influencers per network. Source: Own elaboration.

\begin{tabular}{cccc}
\hline Typology & Madrid & Barcelona & Valencia \\
\hline Candidates & 0.72137661 & 0.18464595 & 0.63058508 \\
Parties & 0.37948120 & 0.44118190 & 0.31722629 \\
Other politicians & 0.27037496 & 0.21172166 & 0.52851631 \\
Media & 0.52749878 & 0.29665883 & 0.55554125 \\
Journalists & 0.47411694 & 0.26946980 & 0.41068487 \\
Opinion-makers & 0.26485281 & 0.37183448 & 0.31129425 \\
Citizens & 0.06096887 & 0.45851371 & 0.26625259 \\
\hline
\end{tabular}

The analysis of the distribution of digital authority in Barcelona shows a very different panorama. In this network, the most influential group are the citizens (EC: 0.45851371) who manage to be in the first position, surpassing the rest of the actors (Table 2). This finding is connected with the thesis that the Internet has favored communicative democratization [22] and diversification in the access of new actors to the digital public debate [2]. The rise of citizens as influencers is associated with an in-depth reconfiguration of digital public discussion and a scenario of reordering the dynamics of influence and power in the digital environment.

At the opposite extreme, the candidates register a very low eigencentrality in Barcelona (EC: 0.18464595). They go from being the first in Madrid to the last here. Even Pedro Sánchez, despite starring in the negotiations to form a Government, does not reach sufficient digital authority to have a minimum degree of social influence in the digital political conversation generated on this network. The independence process aspiring to create an independent state has a strong role in this political community $[46,47]$, and this may explain, in part, the limited relevance of the Spanish government candidates in the digital public debate produced in Barcelona.

The abovementioned same factor causes that, in general terms, the actors most linked to the centers of power register low values of digital authority in Barcelona. This is the case of journalists, the media, and other politicians (Figure 3). Opinion-makers gain prominence, ranking third (EC: 0.37183448). This group, like the citizens, reaches the highest level of digital authority in Barcelona compared to the other two networks studied. These data show that Barcelona has divergent and distinctive social influence parameters in the structuring of the digital public debate [46].

Valencia, which occupies a secondary position concerning the Spanish political, economic, and media centers of power, obtains parameters similar to those observed in Madrid. Thus, candidates once again register a high digital authority. This group is in the first position in this network with a medium-high eigencentrality (EC: 0.63058508) (Table 2). Despite its remoteness from the center of Spanish political life, Valencia reproduces the prominence of these political leaders already detected in Madrid. Additionally, the media and journalists obtain, in this network, values close to those acquired in Madrid (Table 2). These two groups occupy the second and fourth positions in the ranking of digital authority in political conversation in Valencia. Moreover, in these networks, the trend detected in Madrid in the cases of opinion-makers and citizens is repeated. Although both types of actors obtain a higher value of eigencentrality, especially citizens, they do not manage to escape from the last positions (Figure 3 ). This reveals its limited capacity to gain prominence in the digital public debate on this network as well.

However, Valencia registers a significant difference concerning other politicians. These actors, endowed with a low eigencentrality in the other networks, achieve an intermediate level of digital authority here (EC: 0.52851631). A possible explanation is that the level of competition in this secondary network is lower than the detected in Madrid. The fact that Valencia is further away from the centers of power promotes the access and increase of the digital authority of other politicians in the political conversation on Twitter. This causes the exercise of digital influence in this network to be more distributed among the three categories related to political actors. 


\section{Discussion and Conclusions}

The findings make three relevant contributions on who controls the flow of political information and exercises social influence in the political conversation on Twitter. This enables me to identify the influencers-users endowed with the greatest digital authority that can determine the online debate in this digital platform. In the first place, despite the differences registered between the networks analyzed, my data revealed that political and media elites position themselves as the actors with the highest levels of digital authority. Thus, they assume a decisive role as influencers within the public debate on Twitter.

The media and journalists represent $61.54 \%$ of the most relevant users from the perspective of digital authority $(\mathrm{EC}>0.50)$. This shows its high presence within the group of more prominent actors. For their part, the candidates are the dominant type of actor in two of the three networks analyzed (Madrid and Valencia) by registering the highest eigencentrality. In the third network (Barcelona), political parties rank as the second group with the highest digital authority. These results are consistent with those that argue that social media reproduce pre-existing power dynamics that favor media and political positions $[17,26,27,30-33]$.

However, the findings also show that Twitter is beginning to break the monopoly of politicians and journalists on the public debate, albeit in an incipient manner [2,14]. Two pieces of evidence point in this direction. On the one hand, in the Barcelona network, citizens are the group with the highest index of digital authority. On the other, citizens are the second type of actor with the highest numerical presence among the 250 most influential users of this case study. This suggests that the digital environment has increased competition when it comes to affecting the public discussion [24,25]. Connectivity, horizontality, and the low cost of participation in digital platforms have empowered more social actors to access the political conversation, trying to gain prominence in the online debate. This opens the door to redefining the practice of social influence towards a scenario where its exercise is increasingly shared by a greater number of different actors in a context of a progressive, but timid redistribution of power. However, this trend towards democratization and the opening of public debate in the digital environment is still limited. According to this data, in two networks-one of them, the closest to the centers of power-the digital authority of citizens is low or marginal. This means that the changes introduced by Twitter in the digital political conversation still have a moderate impact.

Another contribution of this research is the finding that numerical presence is not directly associated with digital authority. Not all identified influencers have the same ability to determine public debate in the digital environment. This is evidenced by the fact that certain groups of actors, such as citizens or other politicians, place a high percentage of users within the 250 most influential. However, their number is significantly reduced at the highest levels of eigencentrality ( $\mathrm{EC}>0.50$ ). Other politicians move from $42.11 \%$ to $19.23 \%$, while citizens move from $19.23 \%$ of the total to zero. This shows that it is easy to claim social influence on Twitter, but it is difficult to exercise it successfully [48]. In other words, although different types of users can access the digital political conversation, not all have the same options to having great effect in it $[29,36]$. This produces that the highest levels of digital authority to determine the political conversation on Twitter are concentrated in a small number of actors. Only $0.10 \%$ of the total of 24,389 users analyzed are in the highest segment of social influence $(E C>0.50)$ in the case analyzed. These data show that the asymmetries and inequalities established by the economy of attention in social media are also related to the exercise of social influence in political conversation on Twitter [28,35].

Lastly, these findings reveal the importance of the external socio-political context as a driver of digital authority in the public debate on Twitter [49]. There are three reasons for this. First, the same political event generates different dynamics of social influence depending on the network or political community in which the political conversation is inserted. This causes different patterns of digital authority to appear in the interactions between the participating actors. The results obtained by the different types of actors in Madrid, the center of the Spanish political life, and Barcelona, the center of an emerging 
independence process willing to separate from the Spanish State, provide clear evidence in this direction. While in the first case, institutional actors linked to communication and politics predominate, in Barcelona, citizens are the group with the largest digital authority while candidates to the Spanish Government reach the lowest level.

Second, the external socio-political context also manifests its importance in the strong numerical presence obtained by political actors among the most influential users in the political discussion on Twitter. The fact that the event analyzed has a political nature causes the three types of actors from the political system (candidates, parties, and other politicians) to be the majority. In total, they represent $46.16 \%$ of the total of 250 identified influencers. Consequently, the political nature of the event studied encourages the presence of political actors among the influencers.

Third, another element that enables observing the effect of the external socio-political context on digital authority is political initiative. The actors on whom political action is centered outside the network and who, therefore, assume political leadership, achieve larger social influence in the political conversation on Twitter. In this case study, both the political leader (Pedro Sánchez), who led the attempts to form a government, and his party (PSOE), obtained the highest ratios of eigencentrality within their respective groups. Furthermore, most users of the category "other politicians" are members of this party. These three pieces of evidence enabled me to establish that the external sociopolitical context is capable of having an effect in the digital authority of users in the debates on Twitter.

This research has managed to identify the main users and groups operating as influencers in the political conversation concerning a highly relevant political process on Twitter. Moreover, it has made innovative contributions to the characteristics of the digital authority. The fact that this research has used a big data sample of 127.3 million tweets adds robustness and significance to the results. However, given the multifaceted nature and complexity of social influence in digital media, further research is still necessary to understand the scope of this phenomenon and to find out the impact of influencers in digital political communication.

Funding: This research was funded by Spanish State Research Agency-Agencia Estatal de Investigación (AEI), grant number CSO2017-88620-P.

Data Availability Statement: The data is available online at https:/ / polituit.com/comunidades/ (accessed on 15 February 2021).

Conflicts of Interest: The author declares no conflict of interest. The funder had no role in the design of the study; in the collection, analyses, or interpretation of data; in the writing of the manuscript, or in the decision to publish the results.

\section{References}

1. Van Dijck, J. The Culture of Connectivity: A Critical History of Social Media; Oxford University Press: Oxford, UK, 2013.

2. Chadwick, A. The Hybrid Media System: Politics and Power; Oxford University Press: Oxford, UK, 2017.

3. Casero-Ripollés, A.; Feenstra, R.A.; Tormey, S. Old and new media logics in an electoral campaign: The case of Podemos and the two-way street mediatization of politics. Int. J. Press Politics 2016, 21, 378-397. [CrossRef]

4. Pérez-Curiel, C.; Limón-Naharro, P. Political influencers. A study of Donald Trump's personal brand on Twitter and its impact on the media and users. Commun. Soc. 2019, 32, 57-75.

5. Pérez-Curiel, C.; García-Gordillo, M. Indicadores de influencia de los políticos españoles en Twitter. Un análisis en el marco de las elecciones en Cataluña. Estud. Sobre Mensaje Periodístico 2020, 26, 1133-1144.

6. Gass, R.H. Social Influence, Sociology of. In International Encyclopedia of the Social \& Behavioral Sciences, 2nd ed.; James, E., Wright, D., Eds.; Elsevier: Amsterdam, The Netherlands, 2015; pp. 348-354.

7. Pratkanis, A.R. The Science of Social Influence: Advances and Future Progress; Taylor \& Francis: New York, NY, USA, 2007.

8. Cialdini, R.B. Influence: Science and Practice, 5th ed.; Pearson/Allyn \& Bacon: Boston, MA, USA, 2009.

9. Cha, M.; Haddadi, H.; Benevenuto, F.; Gummadi, K.P. Measuring user influence in Twitter: The million follower fallacy. In Proceedings of the Fourth International AAAI Conference on Weblogs and Social Media, Washington, DC, USA, 23-26 May 2010; AAAI Press: Palo Alto, CA, USA, 2010; pp. 10-17. 
10. Lazarsfeld, P.; Berelson, B.; Gaudet, H. The People's Choice: How the Voter Makes Up His Mind in a Presidential Campaign; Columbia University: New York, NY, USA, 1948.

11. Anspach, N.M. The new personal influence: How our Facebook friends influence the news we read. Political Commun. 2017, 34, 590-606. [CrossRef]

12. Izquierdo-Iranzo, P.; Gallardo-Echenique, E. Studygrammers: Learning Influencers. Comun. Media Educ. Res. J. 2020, 28, 111-121. [CrossRef]

13. Israel-Turim, V.; Micó-Sanz, J.L.; Ordeix-Rigo, E. Who Did the Top Media from Spain Started Following on Twitter? An Exploratory Data Analysis Case Study. Am. Behav. Sci. 2021. [CrossRef]

14. Casero-Ripollés, A. Influence of media on the political conversation on Twitter: Activity, popularity, and authority in the digital debate in Spain. Icono 2020, 14, 33-57. [CrossRef]

15. González-Carrión, E.L.; Aguaded, I. The most influencer instagramers from Ecuador. Univ. Rev. De Cienc. Soc. Y Hum. 2019, 31, 159-174.

16. Vizcaino-Verdú, A.; de Casas Moreno, P.; Aguaded, I. Youtubers e instagrammers: Una revisión sistemática cuantitativa. In Competencia Mediática y Digital: Del Acceso al Empoderamiento; Grupo Comunicar: Paraná, Argentina, 2019; pp. $211-220$.

17. Xu, W.W.; Sang, Y.; Blasiola, S.; Park, H.W. Predicting opinion leaders in Twitter activism networks: The case of the Wisconsin recall election. Am. Behav. Sci. 2014, 58, 1278-1293. [CrossRef]

18. Entman, R.M.; Usher, N. Framing in a fractured democracy: Impacts of digital technology on ideology, power and cascading network activation. J. Commun. 2018, 68, 298-308. [CrossRef]

19. López-Meri, A.; Casero-Ripollés, A. El debate de la actualidad periodística española en Twitter: Del corporativismo de periodistas y políticos al activismo ciudadano. Observatorio 2016, 10, 56-79. [CrossRef]

20. Micó, J.L.; Casero-Ripollés, A. Political activism online: Organization and media relations in the case of $15 \mathrm{M}$ in Spain. Inf. Commun. Soc. 2014, 17, 858-871. [CrossRef]

21. Bennett, W.L.; Segerberg, A.; Yang, Y. The strength of peripheral networks: Negotiating attention and meaning in complex media ecologies. J. Commun. 2018, 68, 659-684. [CrossRef]

22. Tewksbury, D.; Rittenberg, J. News on the Internet: Information and Citizenship in the 21st Century; Oxford University Press: Oxford, UK, 2012.

23. Habermas, J. Political communication in media society: Does democracy still enjoy an epistemic dimension? The impact of normative theory on empirical research. Commun. Theory 2006, 16, 411-426. [CrossRef]

24. Casero-Ripollés, A. Research on political information and social media: Key points and challenges for the future. Prof. Inf. 2018, 27, 964-974. [CrossRef]

25. Feenstra, R.A.; Tormey, S.; Casero-Ripollés, A.; Keane, J. Refiguring Democracy: The Spanish Political Laboratory; Taylor \& Francis: New York, NY, USA, 2017.

26. Dagoula, C. Mapping political discussions on Twitter: Where the elites remain elites. Media Commun. 2019, 7, 225-234. [CrossRef]

27. Dubois, E.; Gaffney, D. The multiple facets of influence: Identifying political influentials and opinion leaders on Twitter. Am. Behav. Sci. 2014, 58, 1260-1277. [CrossRef]

28. Fuchs, C. Social Media: A Critical Introduction; Sage: Thousand Oaks, CA, USA, 2017.

29. Kolli, S.; Khajeheian, D. How Actors of Social Networks Affect Differently on the Others? Addressing the Critique of Equal Importance on Actor-Network Theory by Use of Social Network Analysis. In Contemporary Applications of Actor Network Theory; Palgrave Macmillan: Singapore, 2020; pp. 211-230.

30. Guerrero-Solé, F. Interactive behavior in political discussions on Twitter: Politicians, media, and citizens' patterns of interaction in the 2015 and 2016 electoral campaigns in Spain. Soc. Media Soc. 2018, 4, 2056305118808776. [CrossRef]

31. Barberá, P.; Casas, A.; Nagler, J.; Egan, P.J.; Bonneau, R.; Jost, J.T.; Tucker, J.A. Who leads? Who follows? Measuring issue attention and agenda setting by legislators and the mass public using social media data. Am. Political Sci. Rev. 2019, 113, 883-901.

32. Baviera, T. Influence in the political Twitter sphere: Authority and retransmission in the 2015 and 2016 Spanish General Elections. Eur. J. Commun. 2018, 33, 321-337. [CrossRef]

33. Hilbert, M.; Vásquez, J.; Halpern, D.; Valenzuela, S.; Arriagada, E. One step, two step, network step? Complementary perspectives on communication flows in Twittered citizen protests. Soc. Sci. Comput. Rev. 2017, 35, 444-461. [CrossRef]

34. De Ugarte, D. Participación, adhesión e invisibilidad. La venganza de Habermas. Telos Cuad. Comun. Innovación 2014, 98, 97-99.

35. Baeza-Yates, R.; Saez-Trumper, D. Wisdom of the Crowd or Wisdom of a Few? An Analysis of Users' Content Generation. In Proceedings of the 26th ACM Conference on Hypertext \& Social Media; ACM: New York, NY, USA, 2015; pp. 69-74.

36. Barabási, A.L. Network Science; Cambridge University Press: Cambridge, UK, 2016.

37. Riquelme, F.; González-Cantergiani, P. Measuring user influence on Twitter: A survey. Inf. Process. Manag. 2016, 52, 949-975. [CrossRef]

38. Bonacich, P. Some unique properties of eigenvector centrality. Soc. Netw. 2007, 29, 555-564. [CrossRef]

39. Ruhnau, B. Eigenvector-centrality-a node-centrality? Soc. Netw. 2000, 22, 357-365. [CrossRef]

40. Tong, J.; Zuo, L. Dialoguing with Data and Data Reduction: An Observational, Narrowing-Down Approach to Social Media Network Analysis. Journal. Media 2021, 2, 14-29. [CrossRef]

41. Del Fresno García, M.; Daly, A.J.; Sánchez-Cabezudo, S.S. Identifying the new influencers in the Internet Era: Social media and social network analysis. Reis Rev. Española Investig. Sociológicas 2016, 153, $23-42$. 
42. Graham, T.; Jackson, D.; Broersma, M. New platform, old habits? Candidates' use of Twitter during the 2010 British and Dutch general election campaigns. New Media Soc. 2016, 18, 765-783. [CrossRef]

43. Lawrence, R.G.; Molyneux, L.; Coddington, M.; Holton, A. Tweeting Conventions: Political journalists' use of Twitter to cover the 2012 presidential campaign. Journal. Stud. 2014, 15, 789-806. [CrossRef]

44. Wimmer, R.D.; Dominick, J.R. Mass Media Research: An Introduction, 10th ed.; Wadsworth: Boston, MA, USA, 2013.

45. Page, L.; Brin, S.; Motwani, R.; Winograd, T. The Page Rank Citation Ranking: Bringing Order to the Web; Stanford InfoLab: Stanford, CA, USA, 1999.

46. Pérez-Curiel, C.; Jiménez-Marín, G.; García-Medina, I. Influence of the agenda and framing study in the electoral framework of the Procés of Catalonia. Rev. Lat. Comun. Soc. 2020, 75, 27-51.

47. Micó, J.L.; Carbonell, J.M. The Catalan Political Process for Independence: An Example of the Partisan Media System. Am. Behav. Sci. 2017, 61, 428-440.

48. Gruzd, A.; Wellman, B. Networked Influence in Social Media: Introduction to the Special Issue. Am. Behav. Sci. 2014, 58, 1251-1259. [CrossRef]

49. Casero-Ripollés, A.; Micó-Sanz, J.L.; Díez-Bosch, M. Digital public sphere and geography: The influence of physical location on Twitter's political conversation. Media Commun. 2020, 8, 96-106. [CrossRef] 